\title{
PEMANFAATAN JENIS POHON LOKAL CEPAT TUMBUH UNTUK PEMULIHAN LAHAN PASCATAMBANG BATUBARA (STUDI KASUS DI PT. SINGLURUS PRATAMA, KALIMANTAN TIMUR)
}

\author{
Burhanuddin Adman', Boedi Hendrarto², Dwi P. Sasongko ${ }^{3}$ \\ ${ }_{1}^{1}$ Program Studi Magister Ilmu Lingkungan, Program Pascasarjana Universitas Diponegoro, Semarang \\ ${ }^{2}$ Fakultas Perikanan dan Ilmu Kelautan Universitas Diponegoro Semarang \\ ${ }^{3}$ Fakultas Sains dan Matematika Universitas Diponegoro Semarang \\ Email : burhanuddinadman@yahoo.co.id
}

\begin{abstract}
ABSTRAK
Upaya reklamasi di pengusahaan pertambangan yang masuk dalam Kawasan Budidaya Kehutanan (KBK) mengharuskan upaya reklamasi mengikuti aturan yang dikeluarkan oleh Kementerian Kehutanan yang mensyaratkan penanaman jenis pohon lokal. Informasi jenis-jenis pohon lokal yang dapat digunakan untuk revegetasi lahan pascatambang batubara belum banyak tersedia sehingga perlu dilakukan penelitian ini. Penelitian ini bertujuan untuk menganalisis jenis-jenis pohon lokal cepat tumbuh yang berpotensi untuk revegetasi lahan pascatambang batubara di PT. SGP. Metode yang digunakan adalah analisis vegetasi, analisis sifat fisik kimia tanah dan kajian habitat tempat tumbuh tiap jenis serta kemampuan regenerasi alami. Hasil penelitian menunjukkan dari 58 jenis pohon yang ditemukan, terdapat tujuh jenis pohon yang berpotensi untuk digunakan dalam revegetasi lahan pascatambang, yaitu Ficus sp., Fordia splendidissima, Homalanthus populneus, Leea indica, Macaranga hypoleuca, Melastoma malabathricum dan Vernonia arborea. Aspek teknis yang perlu diperhatikan dalam revegetasi dengan ketujuh jenis tersebut adalah sumber benih/bibit, serta teknik penanaman dan pemeliharaan.
\end{abstract}

Kata Kunci: revegetasi, pascatambang batubara; Kecamatan Samboja Kabupaten Kutai Kartanegara

\begin{abstract}
Reclamation efforts in the mining business in the District Forestry Culture (CBC) lead reclamation efforts following the rules issued by the Ministry of Forestry, which requires the planting of local species. Information of local tree species that can be used for post-mining land revegetation of coal has not been widely available so that this research needs to be done. This study aims to analyze the species of fast-growing native trees that potential to plant on revegetation of post-mining coal area in PT. SGP. The method used is the analysis of vegetation, analysis of soil physical and chemical properties and study of the grow habitats of each species and the ability of natural regeneration. The results showed that from 58 species of trees that are found, there are seven species of trees that potential for revegetation post-mining, i.e. Ficus sp., Fordia splendidissima, Homalanthus populneus, Leea indica, Macaranga hypoleuca, Melastoma malabathricum and Vernonia arborea. Technical aspects that need to be considered in revegetation with seven types of sources are source of seeds/seedlings, also planting and maintenance techniques.
\end{abstract}

Keywords: revegetation, post-mining coal; District Samboja Kutai Kartanegara Regency

\section{Pendahuluan}

Kalimantan Timur merupakan salah satu provinsi di Indonesia yang memiliki potensi sumber daya alam yang sangat kaya termasuk bahan tambang. Salah satu hasil tambang dari Kalimantan Timur adalah batubara. Tambang batubara merupakan salah satu produk andalan yang berasal dari
Kalimantan Timur. Gubernur Kalimantan Timur menyebutkan di Kalimantan Timur terdapat 33 izin Perjanjian Karya Pengusahaan Penambangan Batubara (PKP2B) dan 1.386 Izin Usaha Pertambangan (IUP) dengan produksi 220 juta ton per tahun (Media Indonesia, 2012). 
Kegiatan pertambangan terbuka menyebabkan hilangnya keanekaragaman hayati, terjadinya degradasi pada daerah aliran sungai, perubahan bentuk lahan dan terlepasnya logam-logam berat yang dapat masuk ke lingkungan perairan (Rahmawaty, 2002) sehingga perlu dilakukan upaya pemulihan lingkungan melalui reklamasi lahan dan revegetasi. Upaya reklamasi dan revegetasi di pengusahaan pertambangan yang masuk dalam Kawasan Budidaya Kehutanan (KBK) mengacu pada aturan yang telah dikeluarkan oleh Kementerian Kehutanan yang mensyaratkan penanaman jenis lokal (Permenhut No P.4/Menhut-II/2011). Revegetasi dengan tanaman bukan dari jenis pohon lokal akan merubah ekosistem dari kondisinya semula sehingga dikhawatirkan akan menyebabkan hilangnya sebagian jenis tumbuhan maupun hewan. Sementara revegetasi dengan jenis lokal dapat mendukung masuknya jenis-jenis lain dan cenderung dapat memulihkan lingkungan ekosistem mendekati kondisi aslinya (Rahmawati, 2002; Ginoga dan Masripatin, 2009).

Penelitian terdahulu menunjukkan bahwa umumnya penanaman langsung dengan jenis pohon lokal tidak berhasil dengan baik dibanding dengan introduksi jenis pionir. Jenis pohon lokal khususnya yang memiliki nilai ekonomi tinggi umumnya membutuhkan naungan ketika muda sehingga ketika ditanam di tempat terbuka akan mati atau pertumbuhannya terhambat (Mansur, 2010). Informasi jenis-jenis pohon lokal yang dapat digunakan untuk revegetasi lahan pascatambang batubara belum banyak tersedia. Penelitian untuk melihat potensi jenis-jenis lokal terutama jenis pionir dan cepat tumbuh yang dapat digunakan untuk revegetasi lahan pascatambang batubara perlu dilakukan untuk mendukung keberhasilan reklamasi lahan pascatambang batubara.

Keberhasilan penanaman jenis-jenis pohon lokal cepat tumbuh pada lahan pascatambang batubara tergantung pada persiapan penanaman, pemeliharaan tanaman serta pemantauan tanaman (Latifah, 2003). Oleh karena itu perlu disusun suatu rencana revegetasi lahan pascatambang dengan jenis-jenis pohon lokal berdasarkan ketiga hal tersebut. Tujuan penelitian ini adalah menganalisis jenis-jenis pohon lokal cepat tumbuh yang berpotensi untuk revegetasi lahan pascatambang batubara di PT. Singlurus Pratama (SGP).

\section{Metode Penelitian}

\subsection{Lokasi dan Waktu Penelitian}

Penelitian dilakukan di areal reklamasi pascatambang batubara pada PT. SGP, Kecamatan Samboja, Kabupaten Kutai Kartanegara, Kalimantan Timur. Penelitian dilakukan pada bulan Juli - Agustus 2012.

\subsection{Pengumpulan Data}

Identifikasi jenis-jenis pohon lokal dilakukan pada wilayah hutan di sekitar areal tambang dengan analisis vegetasi. Analisis vegetasi dilakukan dengan sampling, yaitu membuat sebuah jalur pengamatan sepanjang $380 \mathrm{~m}$ dengan lebar $20 \mathrm{~m}$. Jalur pengamatan diletakkan secara purposif di sekitar lokasi reklamasi dan dibagi menjadi 19 plot pengamatan berukuran $20 \mathrm{~m} \times 20 \mathrm{~m}$ untuk pengamatan tingkat pohon. Di dalam plot pengamatan pohon, dibuat plot berukuran $5 \mathrm{~m} \times 5 \mathrm{~m}$ dan $2 \mathrm{~m} \times 2 \mathrm{~m}$, masing-masing untuk pengamatan tingkat pancang dan tingkat semai. Tingkat pohon merupakan pohon yang berdiameter $\geq 10 \mathrm{~cm}$, tingkat pancang merupakan permudaan dengan tinggi $\geq 1,5 \mathrm{~m}$ hingga pohon muda dengan diameter $<10 \mathrm{~cm}$, dan tingkat semai merupakan permudaan mulai dari kecambah hingga permudaan dengan tinggi $<1,5 \mathrm{~m}$. Variabel yang diamati adalah jenis pohon, jumlah individu tiap jenis dalam masing-masing plot serta diameter untuk tingkat pancang dan pohon. Jenis-jenis pohon yang tidak dapat diidentifikasi di lapangan dibuat spesimen herbarium dan diidentifikasi di Herbarium Wanariset, Balai Penelitian Teknologi Konservasi Sumberdaya Alam, Samboja.

Sampel tanah diambil untuk membandingkan sifat fisik dan kimia tanah pada wilayah hutan dan areal reklamasi, masing-masing sebanyak tiga sampel. Sampel tanah yang diperoleh dianalisa di Laboratorium Ilmu Tanah Universitas Mulawarman. Penilaian kualitas tanah didasarkan pada Hardjowigeno (1995).

Data analisis vegetasi yang diperoleh dianalisis secara kuantitatif untuk mendapatkan indeks nilai penting (INP) dari masing-masing jenis tumbuhan yang ditemui. Untuk tingkat semai komponen INP yang dihitung meliputi nilai kerapatan relatif dan frekuensi relatif, sedangkan untuk tingkat pancang dan pohon komponen INP 
Adman, B, Hendrarto,B Suryoko, S. 2012. PEMANFAATAN JENIS POHON LOKAL CEPAT TUMBUH UNTUK PEMULIHAN LAHAN PASCATAMBANG BATUBARA (STUDI KASUS DI PT. SINGLURUS PRATAMA, KALIMANTAN TIMUR), . Jurnal Ilmu Lingkungan, Vol 10 (1): 19-25.

http://ejournal.undip.ac.id/index.php/ilmulingkungan

yang dihitung meliputi nilai kerapatan relatif,

frekuensi relatif dan dominansi relatif (Kusmana, 1997). Nilai INP yang tinggi tidak dijadikan dasar pemilihan jenis, karena nilai INP yang tinggi tidak menjamin keunggulan ekologis suatu jenis.

Data hasil identifikasi kemudian diinventarisasi kembali untuk menentukan jenis pohon yang sesuai untuk revegetasi lahan pascatambang. Pemilihan jenis pohon dilakukan secara kualitatif, yaitu dengan memberi skor dan bobot pada tiap kriteria-kriteria pemilihan jenis yang telah ditentukan berdasarkan Permenhut No P.4/Menhut-II/2011 dengan modifikasi. Kriteria dan skor untuk masing-masing kriteria ditampilkan pada Tabel 1.

Setelah ditentukan jenis-jenis yang berpotensi untuk revegetasi lahan pasca tambang, selanjutnya disusun rencana teknis revegetasi dengan menggunakan jenis-jenis tersebut. Penyusunan rencana disusun dengan mempertimbangkan data kondisi lapangan sebelum ditambang (rona awal) dan data kondisi lapangan setelah reklamasi. Data tersebut meliputi rona awal vegetasi serta sifat fisik dan kimia tanah sebelum ditambang dan setelah reklamasi lahan pascatambang. Data kondisi lapangan sebelum ditambang diperoleh dari studi literatur dokumen amdal. Data kondisi setelah reklamasi diperoleh dengan melakukan pengamatan langsung di lapangan dan uji laboratorium.

\section{Hasil dan Pembahasan}

\subsection{Jenis Lokal Alami di Areal PT. SGP}

Berdasarkan hasil analisis vegetasi pada areal yang belum ditambang, ditemukan 58 jenis yang termasuk dalam 27 Famili, dengan rincian 17 spesies pohon pada tingkat semai, 31 spesies pada tingkat pancang dan 34 spesies pada tingkat pohon. 25 jenis pohon dengan nilai INP tertinggi disajikan pada Tabel 2.

Hasil analisis vegetasi ini menunjukkan sebagian besar jenis-jenis pohon yang dijumpai merupakan jenis-jenis pionir dan pohon kecil, bahkan jenis Macaranga gigantea merupakan jenis yang dominan dengan nilai INP yang tinggi. Kondisi hutan yang demikian dapat dikatakan sebagai hutan sekunder muda karena masih ditemukannya jenis-jenis pionir yang dominan. Kehadiran jenis-jenis pionir ini dipicu oleh pembukaan wilayah hutan akibat kebakaran hutan yang terjadi sekitar tahun 1997/1998 dan penebangan yang dilakukan oleh PT. Inhutani. Selain kehadiran jenis-jenis pionir, pada lokasi penelitian juga ditemukan jenis-jenis eksotik yaitu Acacia mangium dan Hevea brassiliensis. Jenis-jenis tersebut merupakan jenis yang awalnya ditanam oleh PT. Inhutani dan kemudian menyebar secara alami di lokasi penelitian.

Tabel 1. Skor untuk masing-masing kriteria.

\begin{tabular}{|c|c|c|c|c|}
\hline No & Kriteria & Bobot (\%) & Skor & Keterangan \\
\hline \multirow[t]{2}{*}{1.} & Habitus & 15 & 1 & Perdu/semak \\
\hline & & & 2 & Pohon \\
\hline & Habitat & 20 & 0 & Non lokal \\
\hline & & & 1 & Lokal, hutan primer \\
\hline & & & 2 & Lokal, hutan sekunder \\
\hline \multirow[t]{3}{*}{3.} & Kemampuan & 10 & 1 & 1 tingkat pertumbuhan \\
\hline & regenerasi & & 2 & 2 tingkat pertumbuhan \\
\hline & & & 3 & 3 tingkat pertumbuhan \\
\hline \multirow[t]{2}{*}{4.} & Nilai Ekonomis & 10 & 0 & Tidak memiliki nilai ekonomis \\
\hline & & & 1 & Memiliki nilai ekonomis \\
\hline \multirow[t]{2}{*}{5 . } & Nilai Ekologis & 15 & 0 & Tidak memiliki nilai ekologis \\
\hline & & & 1 & Memiliki nilai ekologis \\
\hline & Simbiosis & 15 & 0 & $\begin{array}{l}\text { Tidak memiliki simbiosis dengan } \\
\text { mikroorganisme }\end{array}$ \\
\hline & & & 1 & Memiliki simbiosis dengan mikroorganisme \\
\hline \multirow{2}{*}{\multicolumn{2}{|c|}{ 7. Trubusan }} & 15 & 0 & Tidak mudah bertunas dari pangkal batang \\
\hline & & & 1 & Mudah bertunas dari pangkal batang \\
\hline
\end{tabular}


Tabel 2. Nilai INP masing-masing tumbuhan pada tingkat semai di areal PT. SGP.

\begin{tabular}{|c|c|c|c|c|c|}
\hline No & Nama Jenis & Famili & Semai & Pancang & Pohon \\
\hline 1. & Acacia mangium & Fabaceae & - & 64,56 & 4,79 \\
\hline 2. & Antidesma montanum & Euphorbiaceae & 20,44 & - & 7,44 \\
\hline 3. & Artocarpus sp. & Moraceae & - & - & 15,90 \\
\hline 4. & Breynia racemosa & Euphorbiaceae & 9,95 & - & \\
\hline 5. & Cratoxylum sumatranum & Hyperiaceae & - & 12,25 & 8,44 \\
\hline 6. & Ficus sp. & Moraceae & 8,12 & 6,72 & \\
\hline 7. & Fordia splendidissima & Leguminosae & 78,41 & 17,18 & 11,82 \\
\hline 8. & Glochidion tetrapteron & Euphorbiaceae & - & 14,33 & - \\
\hline 9. & Guioa sp. & Sapindaceae & 8,82 & - & \\
\hline 10. & Homalanthus populneus & Euphorbiaceae & 3,93 & 47,50 & 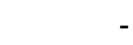 \\
\hline 11. & Leea indica & Leeaceae/Vitaceae & 3,93 & 12,01 & - \\
\hline 12. & Litsea firma & Lauraceae & - & 9,66 & - \\
\hline 13. & Litsea sp. & Lauraceae & 7,42 & 8,04 & 2,22 \\
\hline 14. & Macaranga gigantea & Euphorbiaceae & - & - & 38,29 \\
\hline 15. & Macaranga hypoleuca & Euphorbiaceae & 15,70 & 13,24 & 11,82 \\
\hline 16. & Madhuca sp. & Sapotaceae & - & - & 2,08 \\
\hline 17. & Melastoma malabathricum & Melastomataceae & 6,72 & 17,49 & - \\
\hline 18. & Peronema canescens & Verbenaceae & - & - & 10,22 \\
\hline 19. & Pertusadina euryncha & Rubiaceae & - & - & 11,17 \\
\hline 20. & Ptenandra sp. & Melastomataceae & 5,32 & 12,29 & 11,31 \\
\hline 21. & Schima wallichii & Theaceae & - & - & 21,54 \\
\hline 22. & Scorodocarpus borneensis & Olacaceae & - & 4,38 & 13,76 \\
\hline 23. & Shorea sp. & Dipterocarpaceae & - & 7,24 & 8,67 \\
\hline 24. & Syzygium sp. & Myrtaceae & 8,82 & 2,23 & \\
\hline 25. & Vernonia arborea & Asteraceae & - & 3,05 & 54,08 \\
\hline
\end{tabular}

Sumber: Data Primer (2012)

Dinamika regenerasi yang terjadi tidak berjalan dengan baik. Hal ini terlihat pada minimnya jumlah jenis pada tingkat semai dibandingkan tingkatan di atasnya (pancang dan pohon). Terlihat bahwa dari sepuluh jenis pohon dengan nilai INP tertinggi, lima jenis diantaranya tidak ditemukan pada tingkat pertumbuhan di bawahnya. Jenis-jenis tersebut adalah Macaranga gigantea, Schima wallichii, Artocarpus sp., Pertusadina euryncha, dan Peronema canescens. Begitupun yang terjadi sebaliknya, terdapat beberapa jenis pohon yang baru berkembang sehingga tidak ditemukan pada tingkat pertumbuhan di atasnya.

\subsection{Sifat Fisik dan Kimia Tanah PT. SGP}

Hasil analisis tanah yang dilakukan pada areal hutan dan areal reklamasi menunjukkan tidak terdapat perbedaan pada sifat fisik dan kimia kedua sampel tanah tersebut. Hasil uji sampel tanah disajikan pada Tabel 3 .
Tabel 3. Hasil analisis sifat fisik dan kimia tanah dari hutan alam dan areal reklamasi PT. SGP.

\begin{tabular}{|c|c|c|c|}
\hline \multicolumn{2}{|c|}{ Variabel } & \multirow{2}{*}{$\begin{array}{c}\text { Hutan alam } \\
3,85-4,25\end{array}$} & \multirow{2}{*}{$\begin{array}{c}\text { Areal } \\
\text { Reklamasi } \\
4,57-5,00\end{array}$} \\
\hline $\mathrm{pH} \mathrm{H} \mathrm{H}_{2} \mathrm{O}$ & & & \\
\hline Cation Exchange & $\mathrm{Ca}^{++}$ & $0,47-0,68$ & $0,23-1,78$ \\
\hline$\left(\mathrm{Nh}_{4} \mathrm{O}-\mathrm{Ac}\right) \mathrm{pH} .7$ & $\mathrm{Mg}^{++}$ & $0,56-1,43$ & $0,19-2,29$ \\
\hline \multirow[t]{5}{*}{ (meq./ 100 gr) } & $\mathrm{Na}^{+}$ & $0,05-0,10$ & $0,06-0,40$ \\
\hline & $\mathrm{K}^{+}$ & $0,13-0,26$ & $0,11-0,34$ \\
\hline & KTK & $3,43-5,21$ & $8,16-18,47$ \\
\hline & $\mathrm{Al}_{3}^{+}$ & $0,83-2,83$ & $2,83-6,69$ \\
\hline & $\mathrm{H}^{+}$ & $0,42-1,00$ & $0,36-1,08$ \\
\hline Organic Matter & N. Total & $0,06-0,10$ & $0,04-0,07$ \\
\hline$(\%)$ & C. Org. & $0.65-1,17$ & $0,74-1,55$ \\
\hline Rasio C/N & & $10,6-13,0$ & $15,15-30,52$ \\
\hline Available (Bray & $\mathrm{P}_{2} \mathrm{O}_{5}$ & $0,05-1,20$ & $0,81-3,23$ \\
\hline 1) (ppm) & $\mathrm{K}_{2} \mathrm{O}$ & $43.87-76.80$ & $35,75-99,57$ \\
\hline \multirow[t]{2}{*}{ Saturated (\%) } & Basa & $26,36-63,54$ & $8,86-29,11$ \\
\hline & $\mathrm{Al}$ & $24,31-54,43$ & $18,62-51,79$ \\
\hline Pyrite (\%) & $\mathrm{FeS}_{2}$ & $0,35-1,28$ & $0,14-2,23$ \\
\hline Particle Size & Silt & $8,10-26,30$ & $9,93-19,73$ \\
\hline \multirow[t]{2}{*}{ Analysis (\%) } & Clay & $15,20-37,70$ & $30,07-55,77$ \\
\hline & Total Sand & $46,90-58,50$ & $31,23-55,60$ \\
\hline Texture & & SL-SC & Clay-SCL \\
\hline
\end{tabular}


Adman, B, Hendrarto,B Suryoko, S. 2012. PEMANFAATAN JENIS POHON LOKAL CEPAT TUMBUH UNTUK PEMULIHAN LAHAN PASCATAMBANG BATUBARA (STUDI KASUS DI PT. SINGLURUS PRATAMA, KALIMANTAN TIMUR), . Jurnal Ilmu Lingkungan, Vol 10 (1): 19-25.

http://ejournal.undip.ac.id/index.php/ilmulingkungan

Kelas tekstur tanah pada sampel dari areal hutan alam menunjukkan tekstur lempung berpasir (SL) hingga lempung berliat (SC), sedangkan areal reklamasi menunjukkan tekstur liat (Clay) hingga lempung liat berpasir (SCL). Secara umum terlihat bahwa sifat kimia tanah pada ketiga lokasi tidak menunjukkan perbedaan yang berarti.

Sifat fisik tanah masih menunjukkan kemiripan dengan adanya kandungan pasir dan liat. Kemiripan sifat tanah tersebut disebabkan adanya penghamparan topsoil setelah reklamasi lubang tambang. Topsoil yang digunakan adalah topsoil dari lokasi tambang yang disimpan pada awal kegiatan penambangan. Hal ini menunjukkan secara umum jenis pohon pada areal hutan dapat digunakan untuk revegetasi lahan pascatambang.

Hal yang perlu diperhatikan dalam pemilihan jenis tanaman adalah kemampuan jenis tersebut untuk dapat bertahan pada kondisi kering, karena pada areal reklamasi kondisi tanah sangat terbuka sehingga pada waktu panas tanah menjadi cepat kering dan kandungan liat menyebabkan tanah menjadi padat dan keras.

\subsection{Pemilihan Jenis Pohon untuk Revegetasi Lahan Pascatambang}

Tabel 4. Hasil penilaian potensi jenis-jenis pohon.

\begin{tabular}{llc}
\hline No & \multicolumn{1}{c}{ Nama Jenis } & Total Nilai \\
\hline 1. & Fordia splendidissima & 130 \\
2. & Ficus sp. & 115 \\
3. & Litsea sp. & 115 \\
4. & Macaranga hypoleuca & 110 \\
5. & Syzygium sp. & 110 \\
6. & Archidendron microcarpum & 105 \\
7. & Alstonia sp. & 105 \\
8. & Cratoxylum sumatranum & 100 \\
9. & Homalanthus populneus & 100 \\
10. & Vernonia arborea & 100 \\
11. & Barringtonia macrostacya & 95 \\
12. & Shorea sp. & 95 \\
13. & Eusideroxylon zwageri & 95 \\
14. & Antidesma montanum & 90 \\
15. & Dillenia sp. & 90 \\
16. & Dimocarpus longan & 90 \\
17. & Mischocarpus pentapetalus & 90 \\
18. & Peronema canescens & 90 \\
19. & Schima wallichii & 90 \\
20. & Symplocos fasciculata & 90 \\
\hline
\end{tabular}

Potensi jenis-jenis pohon yang telah diidentifikasi melalui analisis vegetasi untuk revegetasi lahan pascatambang batubara di PT. SGP dinilai berdasarkan tujuh kriteria yang telah ditetapkan sebelumnya. Kriteria masing-masing jenis diolah dari berbagai sumber (Slik, 2009; Wikipedia, 2012; Biotik.org, 2012; Globinmed, 2011). Hasil penilaian potensi untuk 20 jenis pohon dengan skor tertinggi ditampilkan pada Tabel 4 .

Pada Tabel 4. terdapat 10 jenis yang memiliki total nilai tertinggi yaitu Fordia splendidissima, Ficus sp., Litsea sp., Macaranga hypoleuca, Syzygium sp., Archidendron microcarpum, Alstonia sp., Cratoxylum sumatranum, Homalanthus populneus, dan Vernonia arborea. Berdasarkan hasil penilaian, kesepuluh jenis tersebut paling berpotensi untuk revegetasi lahan pasca tambang.

Jenis-jenis dengan nilai INP kecil seperti Alstonia sp., Archidendron microcarpum, Cratoxulum sumatranum, Ficus sp., Litsea sp., dan Syzygium sp. menunjukkan jenis-jenis tersebut sedikit terdapat pada hutan alam di sekitar areal reklamasi. Keterbatasan ini akan menimbulkan kesulitan dalam penyediaan bahan tanaman untuk revegetasi.

Selain sepuluh jenis di atas, ditemukan juga satu jenis tumbuhan yang dapat tumbuh pada kondisi tanah asam yaitu Ixora sp. (Wikipedia, 2012). Jenis ini dapat digunakan untuk revegetasi lahan pascatambang yang memiliki $\mathrm{pH}$ yang sangat masam, karena secara alami sudah beradaptasi dengan kondisi $\mathrm{pH}$ yang sangat rendah.

Secara teori ketujuh jenis pohon tersebut dianggap memiliki kondisi tempat tumbuh yang sesuai dengan lahan reklamasi. Akan tetapi untuk lebih memastikan perlu dilakukan uji penanaman langsung di lapangan. Uji coba penanaman dilakukan dalam sebuah plot yang dimonitor secara berkala.

Jenis-jenis pohon lokal lain yang terdapat pada hutan alam di sekitar areal reklamasi PT. SGP dan memiliki nilai ekonomis seperti Artocarpus sp., Mangifera sp., dan Eusideroxylon zwageri dapat digunakan sebagai tanaman sisipan untuk pengayaan jenis. Jenis-jenis tersebut dapat ditanam 1-2 tahun setelah revegetasi dengan asumsi sudah terjadi perbaikan kondisi lahan dan dapat mendukung pertumbuhan jenis-jenis tersebut. 


\subsection{Rencana Teknis Revegetasi dengan Jenis Lokal}

Kegiatan revegetasi PT. SGP yang awalnya menanam jenis-jenis eksotik, sebaiknya diganti dengan ketujuh jenis lokal yang sudah diidentifikasi sebelumnya. Penanaman jenis-jenis tersebut dapat dilakukan secara monokultur maupun polikultur tergantung kemampuan PT. SGP dalam penyiapan bibit tanaman dari ketujuh jenis tersebut. Akan lebih baik apabila jenis tanaman yang ditanam lebih beragam dalam satu areal karena akan mempercepat suksesi.

Tahapan kegiatan revegetasi dengan jenis lokal dapat mengacu pada tahapan revegetasi yang sudah dilakukan oleh PT. SGP yaitu tahap persiapan, tahap penanaman dan tahap pemeliharaan.

\section{- Tahap Persiapan}

Tahap ini meliputi beberapa kegiatan yaitu penyiapan lahan, penanaman leguminosa penutup tanah dan penyiapan bibit tanaman. Sebelum tanaman utama ditanam, terlebih dahulu ditanam tanaman penutup tanah. Setelah 6 bulan tanaman penutup tanah ini tumbuh di lapangan, barulah tanaman utama ditanam. Penyiapan bibit tanaman dilakukan dengan membuat persemaian untuk menghasilkan bibit yang siap ditanam di lapangan.

Untuk jenis lokal, agar diperoleh bibit yang baik maka perlu diperoleh informasi terkait sumber benih, waktu panen, karakteristik masak fisiologi, cara pengumpulan buah, ekstraksi buah, pembersihan dan sortasi benih, dan penyimpanan benih (Herdiana, 2007).

Pembibitan merupakan langkah awal dalam menyediakan bibit yang bermutu untuk kegiatan penanaman. Mutu bibit yang dihasilkan di persemaian akan menentukan keberhasilan penanamannya di lapangan. Secara umum pembibitan untuk jenis lokal dapat dilakukan secara generatif dengan mengecambahkan langsung buah/benihnya dan secara vegetatif dengan menggunakan stek.

\section{- Tahap Penanaman}

Kegiatan penanaman terkait dengan pengaturan ruang tumbuh (tata letak dan jarak tanam). Tata letak menjadi hal yang harus diperhatikan jika pola tanam yang (C) 2012, Program Studi Ilmu Lingkungan Program Pasca Sarjana UNDIP dikembangkan adalah pola campuran. Jarak tanam yang tepat tidak hanya akan berpengaruh terhadap kecepatan pertumbuhan tanaman, tetapi juga akan berpengaruh terhadap tindakan silvikultur lainnya.

Setelah tanaman penutup tanah ini tumbuh dengan baik di lapangan barulah tanaman utama ditanam. Penanaman dilaksanakan dengan kerapatan 1.000 pohon/ha atau dengan jarak tanam $3 \times 3$ meter. Bibit yang akan ditanam dapat berasal dari biji, cabutan atau stek. Pelaksanaan penanaman dijadwalkan sesuai dengan kondisi hujan di daerah tersebut. Sebaiknya penanaman dilaksanakan pada awal musim penghujan.

- Tahap Pemeliharaan

Tanaman yang sudah ditanam hendaknya dipelihara secara berkala. Pemeliharaan tanaman yang penting untuk dilakukan meliputi penyulaman, penyiangan gulma dan pemupukan.

Penyulaman tanaman dilakukan untuk mengganti tanaman yang mati. Penyulaman dilakukan satu hingga dua bulan setelah penanaman.

Penyiangan gulma berguna untuk membebaskan tanaman dari persaingan tempat tumbuh maupun kebutuhan akan nutrisi. Gulma yang kemungkinan akan tumbuh pada areal reklamasi adalah dari jenis rumputrumputan dan tumbuhan memanjat seperti Mikania sp. Tumbuhan memanjat dapat melilit tanaman dan menghambat pertumbuhan tanaman. Jenis rumput-rumputan yang terlalu rapat kadangkala dapat mendatangkan hama penyakit bagi tanaman sehingga perlu dibersihkan.

Penyiangan gulma dilakukan dengan sistem cemplongan, yaitu membersihkan gulma di sekitar tanaman pada radius $1 \mathrm{~m}$. gulma yang dibersihkan tidak dibuang, tetapi diletakkan di sekitar tanaman yang berfungsi sebagai mulsa. Penyiangan dilakukan setiap 4 bulan hingga tinggi tanaman sudah lebih tinggi dari gulma.

Media tanam merupakan tanah yang berasal dari topsoil tetapi memiliki tingkat kesuburan yang rendah. Pemberian pupuk dapat meningkatkan kesuburan tanah dan mempercepat pertumbuhan tanaman. 
Adman, B, Hendrarto,B Suryoko, S. 2012. PEMANFAATAN JENIS POHON LOKAL CEPAT TUMBUH UNTUK PEMULIHAN LAHAN PASCATAMBANG BATUBARA (STUDI KASUS DI PT. SINGLURUS PRATAMA, KALIMANTAN TIMUR), . Jurnal Ilmu Lingkungan, Vol 10 (1): 19-25.

http://ejournal.undip.ac.id/index.php/ilmulingkungan

\section{Kesimpulan}

1. Ditemukan 34 spesies pada tingkat pohon, 31 spesies pada tingkat pancang dan 17 spesies pohon pada tingkat semai yang tumbuh secara alami pada areal sebelum penambangan.

2. Terdapat 10 jenis pohon lokal yang berpotensi untuk digunakan dalam revegetasi lahan pascatambang batubara di PT. SGP yaitu Fordia splendidissima, Ficus sp., Litsea sp., Macaranga hypoleuca, Syzygium sp., Archidendron microcarpum, Alstonia sp., Cratoxylum sumatranum, Homalanthus populneus, dan Vernonia arborea.

3. Rencana teknis revegetasi lahan pascatambang batubara di PT. SGP disusun berdasarkan sepuluh jenis yang ditemukan dengan memperhatikan aspek penyiapan bibit, penanaman dan pemeliharaannya.

\section{Ucapan Terimakasih}

Penulis menyampaikan terima kasih yang setinggitingginya kepada Kepala Pusat Pembinaan Pendidikan dan Pelatihan Perencana-Badan Perencanaan Pembangunan Nasional (Pusbindiklatren-Bappenas) atas beasiswa dan kesempatan belajar yang diberikan. Terima kasih juga penulis sampaikan kepada Kepala Balai Penelitian Teknologi Konservasi Sumberdaya Alam beserta staf peneliti, dan Pimpinan PT. Singlurus Pratama beserta staf dan karyawan yang telah membantu dalam memberikan akses lokasi penelitian dan proses pengambilan data di lapangan.

\section{Daftar Pustaka}

Ginoga, K. dan Masripatin, N. 2009. Potensi perdagangan karbon pada lahan pascatambang. Prosiding Workshop IPTEK Penyelamatan Hutan Melalui Rehabilitasi Lahan Pascatambang Batubara. Balai Besar Penelitian Dipterokarpa. Samarinda. pp: 2740.

Hardjowigeno, S. 1995. Ilmu Tanah. Edisi Revisi. Penerbit Akademika. Pressindo. Jakarta. p 126.

Herdiana, N. 2007. Potensi Budidaya Jenis Lokal untuk Pembangunan Hutan Rakyat (Damar Mata Kucing, Jelutung, Kayu Bambang Lanang, Kayu Bawang dan Tembesu). Prosiding Workshop Sintesa Hasil Litbang Hutan
Tanaman. Bogor, Desember 2007. Pusat Penelitian dan Pengembangan Hutan Tanaman. Bogor. pp: 163-172.

Kusmana, C. 1997. Metode survey vegetasi. Institut Pertanian Bogor. Bogor.

Latifah, S. 2003. Kegiatan Reklamasi Pada Lahan Pascatambang. $\quad$ http://repository.usu.ac.id/ bitstream/123456789/920/1/hutan-siti1. pdf. diakses tanggal 16 September 2011.

Mansur, I. 2010. Teknik Silvikultur untuk Reklamasi Lahan Bekas Tambang. Seameo Biotrop. Bogor

Rahmawati. 2002. Restorasi Lahan Pascatambang Berdasarkan Kaidah Ekologi. Fakultas Pertanian. Universitas Sumatera Utara. http://library.usu.ac.id/download/fp/hutanrahmawaty5.pdf. diakses tanggal 16 Februari 2010.

Simbolon, H. 2005. Dinamika Hutan Dipterocarp Campuran Wanariset Semboja, Kalimantan Timur Setelah Tiga Kali Kebakaran Tahun 1980-2003. Biodiversitas Vol. 6 No. 2. Halaman: 133-137

Slik, J.W.F. 2009. Plants of Southeast Asia. http://www.asianplant.net/. Diakses tanggal 10 Agustus 2012.

Biotik.org, 2012. Antidesma montanum Blume EUPHORBIACEAE. http://www.biotik.org/ india/species/a/antimont/antimont en.html. Diakses tanggal 14 September 2012.

Globinmed. 2011. Geunsia pentandra (Roxb.) Merr. http://www.globinmed.com/index.php?optio $\underline{\mathrm{n}=\text { com content } \& v i e w=\text { article\&id=62745:geun }}$ sia-pentandra-roxb-merr\&catid=371:g. Diakses tanggal 1 Oktober 2012.

Media Indonesia. 2012. Wow, Cadangan Batu Bara Milik Kaltim 8,3 Miliar Ton. Sabtu, 12 Mei 2012. http://www.mediaindonesia.com/read/2012 /05/12/319259/127/101/ Wow-CadanganBatu-Bara-Milik-Kaltim-83-Miliar-Ton. diakses tanggal 3 Juli 2012.

Wikipedia. 2012. http://en.wikipedia.org/wiki/. diakses tanggal 14 September 2012.

Permenhut RI Nomor P.4/Menhut-II/2011 tentang Pedoman Reklamasi Hutan. 